\title{
THE ROLE OF TRUNK MUSCLES IN SITTING BALANCE CONTROL IN PEOPLE WITH LOW BACK PAIN
}

Marco Freddolini, Siobhan Strike, Raymond Y. W. Lee

\begin{abstract}
The purpose of this study was to examine the muscular activities and kinetics of the trunk during unstable sitting, and to compare healthy and LBP subjects.

Thirty-one healthy subjects and twenty-three LBP subjects were recruited. They were sat on a custom-made chair mounted on a force plate. Each subject was asked to regain balance after the chair was tilted backward at $20^{\circ}$, and then released. The motions of the trunk and trunk muscle activity were examined. The internal muscle moment and power at the hip and lumbar spine joints were calculated using the force plate and motion data.

No significant differences were found in muscle moment and power between healthy and LBP subjects $(\mathrm{p}>0.05)$. The duration of contraction of various trunk muscles and cocontraction were significantly longer in the LBP subjects $(\mathrm{p}<0.05)$ when compared to healthy subjects, and the reaction times of the muscles were also significantly reduced in LBP subjects $(\mathrm{p}<0.05)$.

LBP subjects altered their muscle strategies to maintain balance during unstable sitting, but these active mechanisms appear to be effective as trunk balance was not compromised and the internal moment pattern remained similar. The changes in muscle strategies may be the causes of LBP or the result of LBP with an attempt to protect the spine.
\end{abstract}

Keywords: EMG, lumbar spine, kinetics, low back pain. 


\section{INTRODUCTION}

It has been suggested that the main factors contributing to the stability of the trunk are the intrinsic passive stiffness of its structures and the active contraction of the muscles and that these factors are modulated by the neural system (Crisco and Panjabi, 1991, Gardner-Morse and Stokes, 2001, Panjabi, 1992). Moreover, co-contractions of trunk muscles are present to stabilise the spine during several activities (Granata and Wilson, 2001, Cholewicki et al., 1997). Panjabi (1992) proposed that an alteration of the passive structures may be related to a decrease in the intrinsic stiffness that can then lead to increased muscular activity as a compensatory response in order to sustain the stability of the trunk. This was confirmed by several studies which revealed evidence of increased activities of the trunk muscles due to low back pain (LBP) (Fischer and Chang, 1985, Pirouzi et al., 2006). Increased muscle cocontractions (Granata and Marras, 1995, Marras and Davis, 2001, Marras et al., 2004, Radebold et al., 2000) have also been observed, and may be related to increased spinal stress (Granata and Marras, 1995, Marras et al., 2004) that may lead to injuries and spinal degeneration (Adams et al., 1996, Gallagher et al., 2005).

Moreover, Shum, Crosbie et al. (2007b) studied the effects of back pain on the hip and spine moments during sit-to-stand. They showed that although the moment at the lumbar spine was decreased in the sagittal plane in LBP subjects, moments in transverse and frontal planes were increased. This was believed to be a compensatory strategy to reduce pain. Similar results were found also for the kinematic data of the trunk, where hip and lumbar spine motion pattern were found to be altered as a result of LBP (Shum et al., 2005a, Shum et al., 2005b, Shum et al., 2007a).

The control of dynamic balance of the trunk is not fully understood. In comparison with the standing model used in previous studies (Cholewicki et al., 1997, Pirouzi et al., 2006, Sihvonen et al., 1991, Silfies et al., 2005), the present study employed a sitting position to 
study trunk balance as it would allow us to remove the influence of the legs and to study the role of the trunk in isolation.

The sitting position has been used by some previous authors to study the effects of LBP on trunk muscle activation. Radebold et al. (2000 and 2001 ) measured the response of trunk muscles to sudden perturbation, and found that response time was delayed in LBP subjects. This might suggest that LBP might compromise the motor control mechanism of the spine. Van Dieen et al. (2003) also reported that the ratio of the EMG amplitudes of the antagonist to agonist muscles were increased in LBP patients. However, these previous studies did not examine how these muscle contractions counterbalance the external moment imposed on the spine. In this study, inverse dynamic analysis was used to determine the external moment, which would be correlated with the trunk muscle contraction pattern. In particular, muscle powers were analysed allowing us to evaluate the nature of the contractions, whether they were eccentric or concentric.

One limitation of the inverse dynamic model was that it did not allow us to study cocontraction of muscles which may be present during the perturbation (Granata and Marras, 1995, Marras et al., 2001, Marras et al., 2004, Radebold et al., 2000). In this study, such limitation was addressed by collecting EMG signals of the trunk muscles. The evaluation of any possible co-contraction would significantly increase our understanding of how various muscles contribute to the muscle moment and power. We also extended our inverse dynamic analysis to the hips so that we could evaluate the interaction between the spine and hip joint loads.

The purpose of this study was to examine the muscular activities and kinetics of the trunk during unstable sitting, and to determine the differences in these responses between healthy and low back pain (LBP) subjects. It was hypothesised that there would be differences 
between LBP and healthy subjects in moment and power distribution between hip and spine joints, and in trunk muscle activation patterns.

\section{METHODS}

\section{Subjects}

Thirty-one healthy subjects without history of LBP, and twenty-three subjects with sub-acute (>6 weeks) LBP (Savigny et al., 2009) were recruited for the study using advertisements in the University of Roehampton and in public locations near the university. Subjects' characteristics are summarised in Table 1 . They were found not to be significantly different between LBP and healthy subjects ( $p>0.05$ ). Exclusion criteria for all subjects were the presence of ankylosing spondylitis, fractures/dislocations of the spine or hips, history of spinal or hip surgery, pregnancy, neurological disorders, cancer and osteoporosis. A visual analogue scale (VAS) was used to record the perceived severity of pain experienced by LBP and the functional ability evaluated by Oswestry Disability Questionnaire (Fairbank and Pynsent, 2000). LBP subjects were also asked to indicate where the pain was located (bilateral, left or right side). The study was approved by the Ethics Committee of the University of Roehampton. All subjects were asked to read and sign an informed consent form prior starting the experiment.

\section{Equipment}

A custom-made chair (Figure 1) was built which was restricted to swing in the sagittal plane. It had feet and leg support to restrict the knee and ankle to a $90^{\circ}$ angle, and adjustable belts to restrict lower limb movements. The base of the chair was mounted onto a force platform (Type 9281B, Kistler ${ }^{\mathrm{TM}}$ ). The chair was built from wood, as metal would interfere with the electromagnetic field generated by the transmitter of the motion tracking system. The 
swinging mechanism was provided by two low friction ball bearings. Mechanical stops prevented the chair from tilting more than $20^{\circ}$ backward and forward.

The movement of the lumbar spine was measured using a three-dimensional motion track system (3SPACE FASTRAK®, Polhemus Inc.) recording at $40 \mathrm{~Hz}$. Two sensors were placed on the subjects' back, one at the sacrum level and one at the first lumbar vertebral level. One further sensor was placed on the chair to track its rotation, which was also used to define the rotation of the lower limbs. Integral dry reusable electromyographic (EMG) electrodes (Biometrics Ltd,, type Nos. SX230) were connected to the DataLINK system (DLK900, Biometrics Ltd., Gwent, UK) to record the electrical activities of the paraspinal muscles at a sampling rate of $1000 \mathrm{~Hz}$. The diameter of each electrode was $1 \mathrm{~cm}$ and interelectrode distance was $2 \mathrm{~cm}$. The EMG signals were amplified using a single differential amplifier with an input impedance of $10^{7} \mathrm{M} \Omega$, a common mode rejection ratio of $110 \mathrm{~dB}$, a gain of 1000 and bandwidth 20-460 Hz. After skin preparation with alcohol and shaving of hair, the surface electrodes were secured with double-sided tape bilaterally on the erector spinae $(3 \mathrm{~cm}$ lateral to the L3 spinous process), rectus abdominus, external and internal oblique, according with Thomas and Lee (2000). Reference electrode was positioned over the left medial malleolus process. The chair was placed over the force platform recording at $150 \mathrm{~Hz}$, in order to determine the loads that acted on the system formed by the chair and the subject. Measure Foundry (Data Translation Inc.) software was used to synchronize data acquisition of the devices and to integrate motion and force data. MATLAB® (R2007b, MathWorks Inc.) was used for data re-sampling and analysis and SPSS (SPSS: An IBM Company) was used for statistical analysis.

\section{Protocol}


Subjects were strapped to the chair with the lower limbs and pelvis immobilised, and they were asked to fold their arms across the chest facing forward. The height of the feet support was adjusted to allow the subject to sit in a comfortable position (figure 1). Initially, the subject was tilted twice backwards and forwards by the researcher in a controlled manner to show the range of motion (ROM) of the chair, and then the balanced position (with the chair parallel to the floor) was shown to the subject. Thereafter, the researcher tilted the chair into an angle between $0-20^{\circ}$ and following release, the subject was asked to return to the balanced position and maintain it for $5 \mathrm{~s}$. This familiarization protocol ended when the subject was able to find the balanced position and to hold it for at least 5 seconds for three repetitions. All subjects were able to complete the familiarization protocol. After the familiarization protocol, the chair was tilted $20^{\circ}$ backward. The chair was released without warning and they were asked to achieve the steady balanced position. All subjects were able to reach the balanced position within three attempts. The average number of attempts of healthy and LBP subjects were $1.2 \pm 0.3$ and $1.5 \pm 0.4$, and there were no significant differences between the two groups ( $p>0.05$ ). The trial was considered to be successful when the subject was able to reach a steady balanced position without engaging the mechanical stops and maintaining it for 1 second with a maximal oscillation of $\pm 1^{\circ}$.

\section{Analysis}

The joint moments represented the net effect of the muscles to balance the external moments acting on the hip and lumbar spine. In this manner when external moment was tending to flex, the muscle moment would be extensor moment, and vice versa.

Inverse dynamic equations were used to derive the muscle moment acting at the hip and lumbar spine joints using data from the force platform and the motion tracking system (figure 2). Hip joint centre was defined as the caudal endpoint of the trunk defined by Zatsiorsky 
(Zatsiorsky, 2002) and located using digitised landmark points. Centre of mass and inertial properties were calculated using the nonlinear regression equation from Zatsiorsky

(Zatsiorsky, 2002). The following equation was used to derive muscle moment at the hip $M_{H}$ and that at the lumbar spine $M_{S}$ :

$$
\begin{gathered}
M_{H}+I_{H} \varepsilon_{S}+F_{R y} d_{1}+F_{R x} d_{2}-m_{L} g d_{3}=0 \\
M_{S}+I_{P} * \varepsilon_{P}-M_{H}+F_{H x} * d_{4}-F_{H y} * d_{5}+m_{H} * g * d_{6}=0
\end{gathered}
$$

where $I_{H}$ and $I_{P}$ represent the moment of inertia of the lower limbs and the pelvis; $\varepsilon_{s}$ and $\varepsilon_{p}$ are angular accelerations of hip and pelvis; $m_{L}$ and $m_{H}$ are the mass of the lower limbs and pelvis; $R, H$ and $S$ represent respectively the position of the centre of rotation of the swinging chair (the free-rotating hinge of the chiar which transmitted the forces $F_{R x}, F_{R z}$ ), the hip joint centre and L5-S1 joint centre; $C m_{L O W}$ is the centre of rotation of the swinging chair (this location was determined by suspending the chair in space and finding the suspension point where the chair was balanced and did not rotate), $C m_{P E L}$ is the centre of mass of the pelvis (Zatsiorsky, 2002); $F_{x}, F_{z}, F_{R x}, F_{R z}$ are forces components (figure 2) and $d_{1}, d_{2}, d_{3}, d_{4}, d_{5}$ are distances shown in figure 2 (they were measured using the Fastrak machine by digitising the two end points of the distances) and $g$ gravitational acceleration.

Angular velocity and acceleration were obtained from differentiation of displacement data acquired by Fastrak machine using the 5-point central difference method (Robertson et al., 2013). Muscle power was then calculated by multiplying the muscle moment and the corresponding joint angular velocity.

Muscle moment and power data were analysed together to understand the nature of the lumbar spine muscles contractions. When lumbar spine flexor moment was present, a positive power indicated concentric contraction of the lumbar spine flexors while a negative power indicated an eccentric contraction. Similar interpretation could be made to the lumbar spine 
extensor behaviour in presence of extensor moment. The role of the muscles in contributing to the moment and power was further studied by EMG.

Anthropometric measures were used to normalize moment and power data according to Hof (Hof, 1996) in the following manner:

Normalised moment $=\frac{M}{m g l} ;$ Normalised power $=\frac{P}{m g^{1 / 2} l^{3 / 2}}$

where $\mathrm{m}=$ body mass $(\mathrm{kg}) ; \mathrm{g}=$ gravity acceleration $\left(9.81 \mathrm{~m} / \mathrm{s}^{2}\right) ; \mathrm{l}=$ leg length $(\mathrm{m})$.

The root mean square (RMS) of the joint velocity, normalised moment and normalised power were calculated from the beginning (i.e. the onset of the tilt) to the end of the trial (i.e. when balance was achieved). The maximum normalised moment, and the peak-to-peak (the absolute difference between the maximum and minimum values) velocity and normalised power were also determined during the same time period.

EMG data were band-pass filtered (5th order butterworth filter 10-500 Hz) and then rectified. The linear envelope obtained by applying a low pass filter (5th order butterworth filter with 4 $\mathrm{Hz}$ cut-off). The amplitude of EMG data was normalised using the mean dynamic activity method (Yang and Winter, 1984), whereby the mean of the linear envelope was calculated and considered as $100 \%$ of the amplitude.

To detect the on-set and the off-set of each muscle, the method of Stokes, Gardner-Morse et al. (Stokes et al., 2000) was used. A threshold was calculated as the sum of the mean of the EMG data recorded while the subject was resting plus 3 standard deviation (SD) of that mean; the onset of EMG activity was considered to be the time when the signal exceeded this threshold for at least $150 \mathrm{~ms}$. The off-set time was detected using the same threshold but analysing the EMG signal from the end of a contraction. Muscular activity was considered to be active between the onset and offset times, and the duration of contraction was expressed as percentage of the total time of the trial. Total co-contraction was considered to occur when all the trunk muscles studied were active using the above definitions of onset and offset times. 
The percentage of number of subjects exhibiting total co-contraction of all the muscles at all time instants were then determined.

Moreover, muscle reaction time was defined as the time duration between the starting point of the experiment (defined as the point where the chair angle deviated more than 3 SD from the mean of the chair angle calculated for $0.2 \mathrm{~s}$ time window prior to the release) and the first on-set of the muscular activity.

\section{Statistics}

Multivariate ANOVA was used to evaluate differences between LBP and healthy subjects in the joint velocity, moment and power; the muscle reaction time and the duration of total cocontraction. Gender was found to have no effect on any of the dependent variables $(p>0.05)$ and so male and female data were combined together for statistical analysis between each subject group. For all statistics significant level was set at 0.05 .

In order to study any asymmetry in muscle contraction, cross-correlation was performed between left and right sides for internal oblique, external oblique, rectus abdominis and erector spinae for each subject. This procedure was used to compare the similarity of the waveforms of the EMG signals of the two sides. The correlation values may range from 0 to 1, 0 being no correlation between the left and right side contraction, and 1 exactly the same EMG waveforms on the two sides. The differences in the correlation coefficients between the LBP and healthy subjects were compared as one of dependent variables in the MANOVA test mentioned above.

\section{RESULTS}


Hip angular velocity variables were found to be significantly increased in LBP subjects $(\mathrm{p}<0.05)$, (Table 2). Lumbar spine joint velocity tended to be decreased for the LBP subjects, but such difference was not statistically significant $(\mathrm{p}>0.05)($ Table 2$)$.

There were no significant differences between LBP and healthy subjects regarding the normalised hip and lumbar spine powers and muscle moments (Table 2) (p>0.05). Figure 3 illustrates the typical kinetic and EMG responses of a LBP subject, after releasing the chair. The moment was positive throughout the trial, indicating that the muscles were producing a net flexor moment. The EMG activities show that there were co-contraction of the trunk muscles. The linear envelopes of the EMG signals generally follow the patterns of the moment and power curves, indicating that the muscle contraction contributed to the joint moment and power. In this particular subject, the power remained positive from the beginning of the trial until 1.1s, indicating that during the co-contraction, concentric flexor power was stronger than the eccentric extensor power, resulting in a net positive power; from $1.1 \mathrm{~s}$ until $1.7 \mathrm{~s}$ the power became negative and the pattern reversed, with concentric extensors power stronger than the eccentric flexor power. Before reaching the balanced position the power became positive again. As shown in Figure 3, muscular contractions started soon after chair release, and this pattern was similarly observed in all subjects. The mean reaction times of all muscles of the LBP subjects was significantly reduced when compared to the healthy subjects $(\mathrm{p}<0.05)$ (Figure 4). Furthermore, the percentage duration of contractions of the trunk muscles of LBP subjects were longer when compared with healthy subjects $(\mathrm{p}<0.05)$ (Figure 5).

Figure 3 shows a horizontal bar indicating the time period when there was total cocontraction of all muscles in this LBP subject (i.e. when all trunk muscles were active). 
Figure 6 illustrates that at most of the time instants, the percentages of number of LBP subjects which showed total muscle co-contraction were increased when compared to healthy subjects. The mean percentage of all time instants was significantly higher for LBP subjects $(\mathrm{p}<0.05)(12.6 \%$ for healthy and $35.2 \%$ for LBP subjects).

Table 3 shows the results of the cross correlation analysis of the left and right muscles. The correlation coefficient of the erector spinae was significantly reduced in LBP subjects $(\mathrm{P}<0.05)$, showing a loss of symmetry pattern in this muscle group. However, no significant differences in the correlation of the abdominal muscles $(\mathrm{P}>0.05)$ were founded.

\section{DISCUSSION}

During the balancing task, trunk muscles generated hip and lumbar spine moments in order to counterbalance the external moments and to permit to the subjects to regain the balanced position. The results showed that moments generated by LBP subjects were similar in pattern and magnitude to those generated by healthy subjects. As shown by Figure 3, muscle moments oscillated until the balancing position was reached. The joint powers provided information about the nature of the muscle contraction, distinguishing between eccentric and concentric contraction as described above. Similar to the muscle moments, muscle power data were not significantly different in magnitude between the two groups of subjects. From a kinetic point of view, there were no alterations due to LBP, but the kinematic and EMG results showed that LBP subjects did perform the task differently. A significant finding is that the hip angular velocity is significantly increased in LBP subjects. LBP appears to alter the hip and spine motion interaction, and such finding is in agreement with that reported by Shum et al (2007a and 2007b). It is also shown that muscular activation patterns are grossly different in the LBP subjects (Figure 5). It may be concluded that LBP subjects maintain 
balance and produce similar trunk loads, but they used different motion and muscle recruitment strategies.

The decrease in muscle reaction time observed in this study does not agree with the results of previous research (Radebold et al., 2001), which reported the opposite. This could be due to the differences in the activities being examined or how the experiment was conducted. The experiment of Radebold et al was done in a sitting position with the lower limbs fixed to the ground, whereas in this study, the trunk was subjected to constantly changing moment due to the swing of the chair. This was a more challenging task and might therefore require much shorter reaction times of the muscles to balance the body. It is noted that about $50 \%$ of the LBP subjects in our study had some of the muscles already activated before the start of the trial, suggesting that LBP subjects were preparing for the swing. The decrease in the reaction time may also relate to such pre-activation of the muscles. Recent studies (Pruszynski et al 2014) have shown that motor responses to mechanical perturbations are task and goal dependent, and forward feedback might modulate the response times of the muscles.Future research should further investigate the precise nature of these neurological mechanisms in LBP subjects.

There were increased number of people with co-contraction of muscles among the LBP subjects, indicating that the agonist and antagonist muscles were actively working together to balance the external moment. These results were in accordance with previous studies which also found increased trunk muscular activity in LBP subjects during various activities (Cholewicki et al., 1997, Sihvonen et al., 1991, Silfies et al., 2005), and in responding to an external perturbation in a semi-seated position (Hodges et al., 2009). It is possible that the changes in muscle activity may be a compensatory strategy to account for the decrease in the intrinsic stiffness due to LBP (Panjabi, 1992). It may be a protective response to pain in order to limit spine motion and reduce the risks of further damage to the spine tissue (Fischer and 
Chang, 1985). However, it is also possible that the changes in EMG may be the cause of back pain rather than a response to pain. The EMG response in LBP subjects could be less efficient than those in healthy subjects because more muscular activity and increased co-contraction is required to balance external moments. The prolonged increase in muscular activity may then lead to increasing spinal stress (Granata and Marras, 1995, Marras and Davis, 2001, Marras et al., 2004), muscle fatigue and contracture (Thomas and Lee, 2000), resulting in pain. As this is a cross-sectional study, although we are able to examine the effect of pain on muscular responses, the cause and effect of the association cannot be ascertained, and this needs to be further investigated in future study.

Clinically, if it is shown that the changes in EMG pattern is a cause of LBP, it would be useful to explore the feasibility of using the swinging chair as a biofeedback training tool for LBP patients to restore the motor control of the trunk muscles. The current experimental set up may also be provided with a visual tool that can be used to show a target that the subject should achieve in trunk control. Combination of the visual training tool with EMG of trunk muscles can provide useful information about muscles coordination and may be used to evaluate the progress of rehabilitation programme.

On the other hand, if the changes in EMG are shown to be a consequence of pain, the above biofeedback training may not be helpful. Therapeutic intervention should be directed to relieve pain so that the EMG patterns could be restored, avoiding continued increase in spinal stress and aggravation of the symptoms (Granata and Marras, 1995, Marras and Davis, 2001, Marras et al., 2004). However, it is possible that pain and EMG changes are operating in a viscous circle, reinforcing each other leading to a chronic condition. Therapy should help break this viscous circle, with pain relief to reduce symptoms together with exercise to restore muscular function. 
This study demonstrates that LBP subjects were able to perform the balance tasks with similar kinetic profile as the healthy subjects and the ability to perform the task was not compromised, despite the changes in muscle response. This may suggest clinicians should encourage patients to remain active rather than to avoid movements.

\section{CONCLUSIONS}

The present study shows how trunk muscles generated an internal moment to counterbalance the external perturbation and regain balance during unstable sitting. There were altered muscle contraction patterns and significant increases in the percentage of LBP subjects in cocontraction. These active mechanisms appear to be effective in maintaining trunk balance. This study clearly shows the association between LBP and changes in muscle responses, but the cause and effect of this association is still uncertain. Longitudinal studies should be carried out in the future to examine this association; as such understanding will have significant implications on treatment planning. Future research should also look at the effects of more complicated tasks (e.g. random three-dimensional sitting perturbation) on the muscle response of the lumbar spine.

\section{ACKNOWLEDGEMENT}

This work was supported by a research grant funded by The Arthritic Association.

\section{REFERENCES:}

Adams, M. A., Mcmillan, D. W., Green, T. P. \& Dolan, P. 1996. Sustained Loading Generates Stress Concentrations in Lumbar Intervertebral Discs. Spine, 21, 434-438. 
Cholewicki, J., Panjabi, M. M. \& Khachatryan, A. 1997. Stabilizing Function of Trunk Flexor-Extensor Muscles Around a Neutral Spine Posture. Spine, 22, 2207-2212.

Crisco, J. J. \& Panjabi, M. M. 1991. The intersegmental and multisegmental muscles of the lumbar spine - a biomechanical model comparing lateral stabilizing potential. Spine, 16, 793-799.

Fairbank, J. C. T. \& Pynsent, P. B. 2000. The Oswestry Disability Index. Spine, 25, 2940-2953.

Fischer, A. A. \& Chang, C. H. 1985. Electromyographic Evidence of Paraspinal Muscle Spasm During Sleep in Patients With Low Back Pain. The Clinical Journal of Pain, 1, 147-154.

Gallagher, S., Marras, W. S., Litsky, A. S. \& Burr, D. 2005. Torso Flexion Loads and the Fatigue Failure of Human Lumbosacral Motion Segments. Spine, 30, 2265-2273 10.1097/01.brs.0000182086.33984.b3.

Gardner-Morse, M. G. \& Stokes, I. a. F. 2001. Trunk stiffness increases with steady-state effort. Journal of Biomechanics, 34, 457-463.

Granata, K. P. \& Marras, W. S. 1995. The influence of trunk muscle coactivity on dynamic spinal loads. Spine (Phila Pa 1976), 20, 913-919.

Granata, K. P. \& Wilson, S. E. 2001. Trunk posture and spinal stability. Clinical Biomechanics, 16, 650-659.

Hodges, P. W., Van Den Hoorn, W., Dawson, A. \& Cholewicki, J. 2009. Changes in the mechanical properties of the trunk in low back pain may be associated with recurrence. Journal of Biomechanics, 42, 61-66.

Hof, A. L. 1996. Scaling gait data to body size. Gait \&amp; Posture, 4, 222-223.

Marras, W. S. \& Davis, K. G. 2001. A non-MVC EMG normalization technique for the trunk musculature: Part 1. Method development. Journal of Electromyography and Kinesiology, 11, 1-9.

Marras, W. S., Davis, K. G., Ferguson, S. A., Lucas, B. R. \& Gupta, P. 2001. Spine Loading Characteristics of Patients With Low Back Pain Compared With Asymptomatic Individuals. Spine, 26, 2566-2574.

Marras, W. S., Ferguson, S. A., Burr, D., Davis, K. G. \& Gupta, P. 2004. Spine loading in patients with low back pain during asymmetric lifting exertions. The Spine Journal, 4, 64-75.

Panjabi, M. M. 1992. The stabilizing system of the spine .1. function, dysfunction, adaptation, and enhancement. Journal of Spinal Disorders, 5, 383-389.

Pirouzi, S., Hides, J., Richardson, C., Darnell, R. \& Toppenberg, R. 2006. Low back pain patients demonstrate increased hip extensor muscle activity during standardized submaximal rotation efforts. Spine, 31, E999-E1005.

Pruszynski JA1, Omrani M \& Scott SH 2014. Goal-dependent modulation of fast feedback responses in primary motor cortex. J Neurosci. 34(13), 4608-17.

Radebold, A., Cholewicki, J., Panjabi, M. M. \& Patel, T. C. 2000. Muscle response pattern to sudden trunk loading in healthy individuals and in patients with chronic low back pain. Spine, 25, 947-954. 
Radebold, A., Cholewicki, J., Polzhofer, G. K. \& Greene, H. S. 2001. Impaired Postural Control of the Lumbar Spine Is Associated With Delayed Muscle Response Times in Patients With Chronic Idiopathic Low Back Pain. Spine, 26, 724-730.

Robertson, G., Caldwell, G., Hamill, J., Kamen, G. \& Whittlesey, S. 2013. Research Methods in Biomechanics, $2 E$, Human Kinetics Publishers.

Savigny, P., Kuntze, S., Watson, P., Underwood, M., Ritchie, G., Cotterell, M., Hill, D., Browne, N., Buchanan, E., Coffey, P., Dixon, P., Drummond, C., Flanagan, M., Greenough, C., Griffiths, M., Halliday-Bell, J., Hettinga, D., Vogel, S. \& Walsh, D. 2009. NICE Clinical guideline 88: Low back pain: early management of persistent non-specific low back pain, Full guideline.

Shum, G. L. K., Crosbie, J. \& Lee, R. Y. W. 2005a. Effect of low back pain on the kinematics and joint coordination of the lumbar spine and hip during sit-to-stand and stand-to-sit. Spine, 30, 1998-2004.

Shum, G. L. K., Crosbie, J. \& Lee, R. Y. W. 2005b. Symptomatic and asymptomatic movement coordination of the lumbar spine and hip during an everyday activity. Spine, 30, E697-E702.

Shum, G. L. K., Crosbie, J. \& Lee, R. Y. W. 2007a. Movement coordination of the lumbar spine and hip during a picking up activity in low back pain subjects. European Spine Journal, 16, 749-758.

Shum, G. L. K., Crosbie, J. \& Lee, R. Y. W. 2007b. Three-dimensional kinetics of the lumbar spine and hips in low back pain patients during sit-to-stand and stand-to-sit. Spine, 32, E211-E219.

Sihvonen, T., Partanen, J., Hanninen, O. \& Soimakallio, S. 1991. Electric behavior of low-back muscles during lumbar pelvic rhythm in low-back-pain patients and healthy controls. Archives of Physical Medicine and Rehabilitation, 72, 1080-1087.

Silfies, S. P., Squillante, D., Maurer, P., Westcott, S. \& Karduna, A. R. 2005. Trunk muscle recruitment patterns in specific chronic low back pain populations. Clinical Biomechanics, 20, 465-473.

Stokes, I. a. F., Gardner-Morse, M., Henry, S. M. \& Badger, G. J. 2000. Decrease in trunk muscular response to perturbation with preactivation of lumbar spinal musculature. Spine, 25, 1957-1964.

Thomas, K. \& Lee, R. Y. W. 2000. Fatigue of abdominal and paraspinal muscles during sustained loading of the trunk in the coronal plane. Archives of Physical Medicine and Rehabilitation, 81, 916-920.

Van Dieen, J. H., Cholewicki, J. \& Radebold, A. 2003. Trunk muscle recruitment patterns in patients with low back pain enhance the stability of the lumbar spine. Spine, 28, 834-841.

Yang, J. F. \& Winter, D. A. 1984. Electromyographic amplitude normalization methods - improving their sensitivity as diagnostic-tools in gait analysis. Archives of Physical Medicine and Rehabilitation, 65, 517-521.

Zatsiorsky, V. M. 2002. kinetics of human motion, United State of America, Human Kinetics 


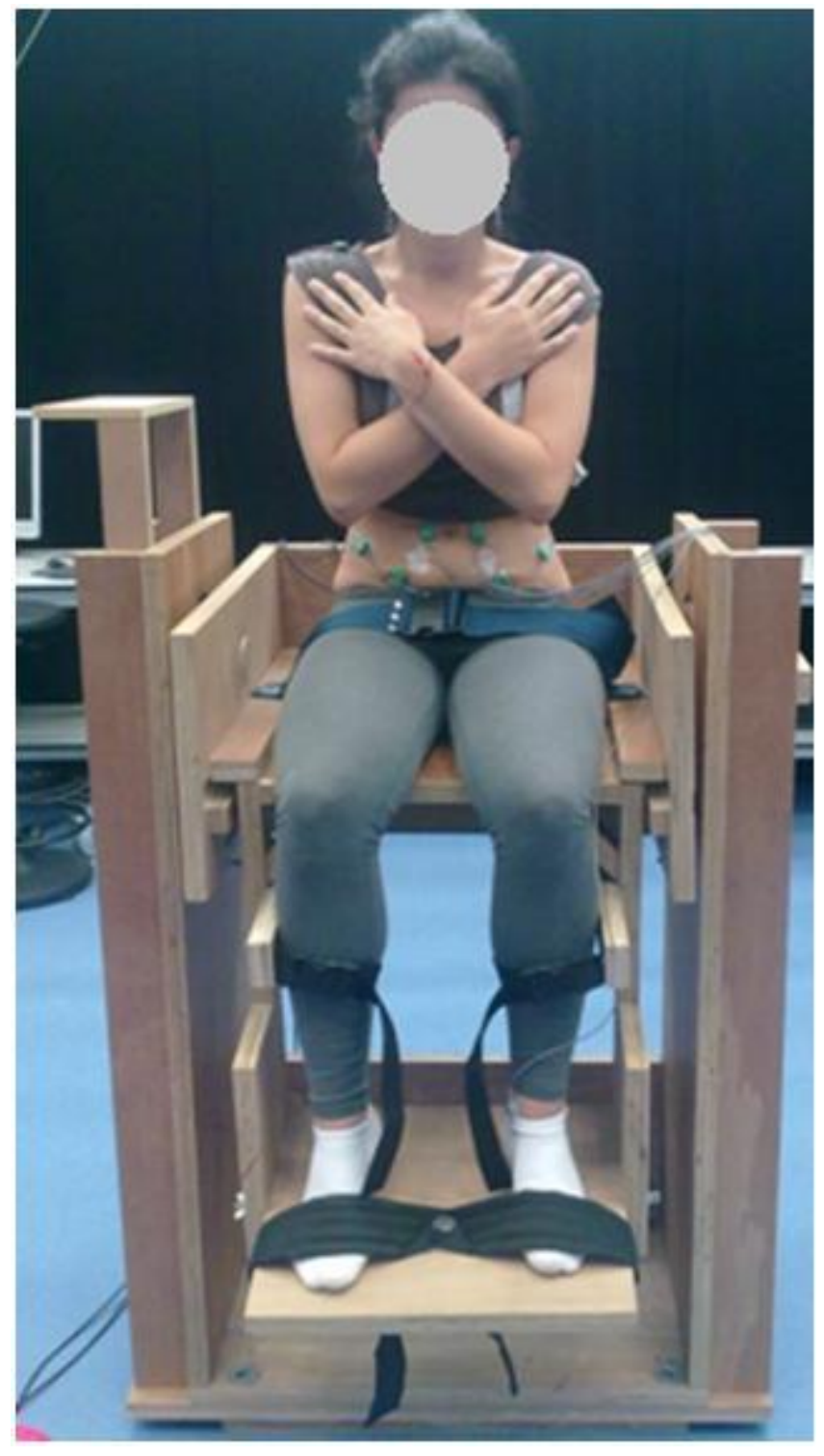

Figure 1: Subject on the custom-made swinging chair; 


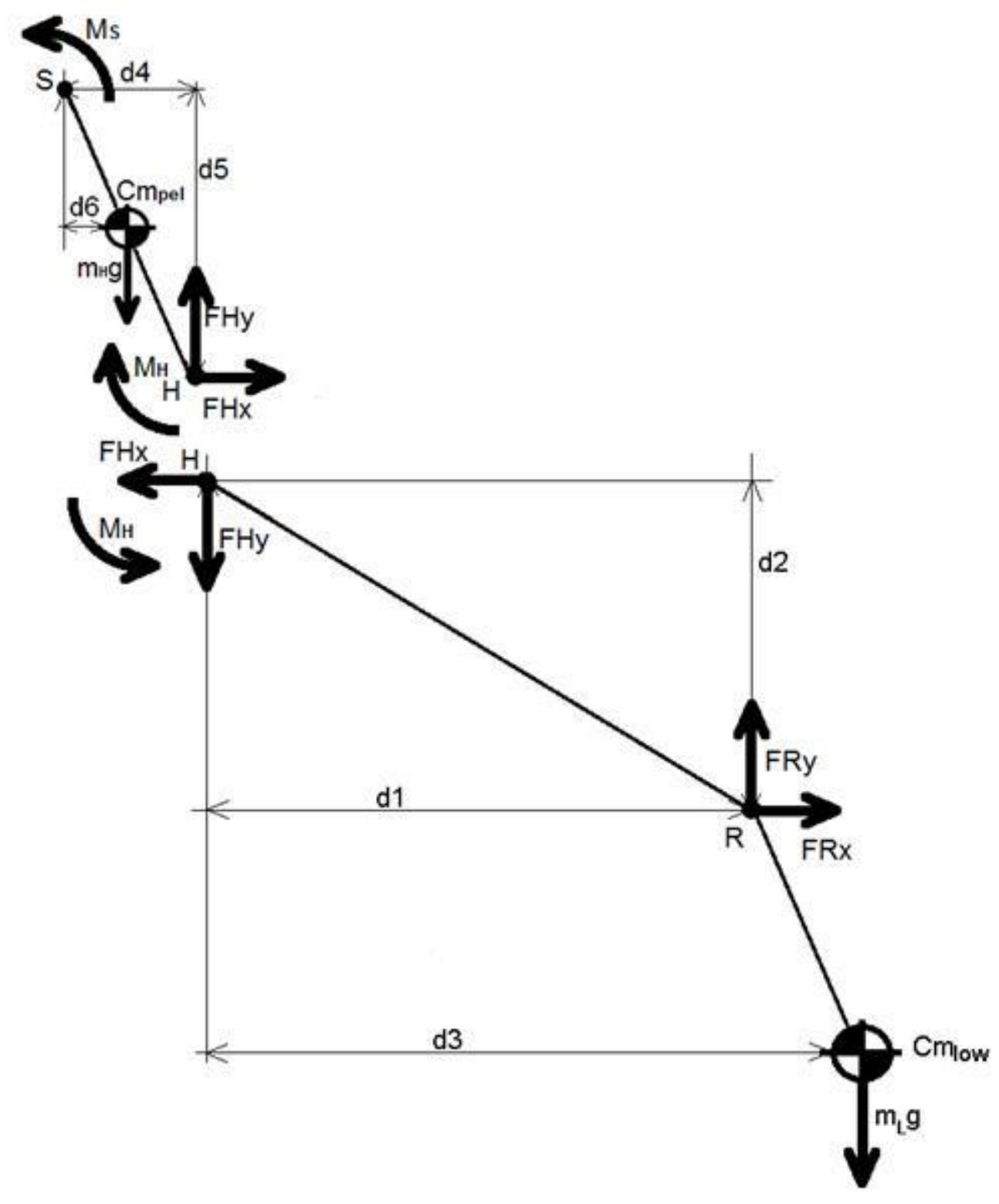

Figure 2: Free body diagram for the calculation of the moment at the hip joint and at the lumbar spine joint. 


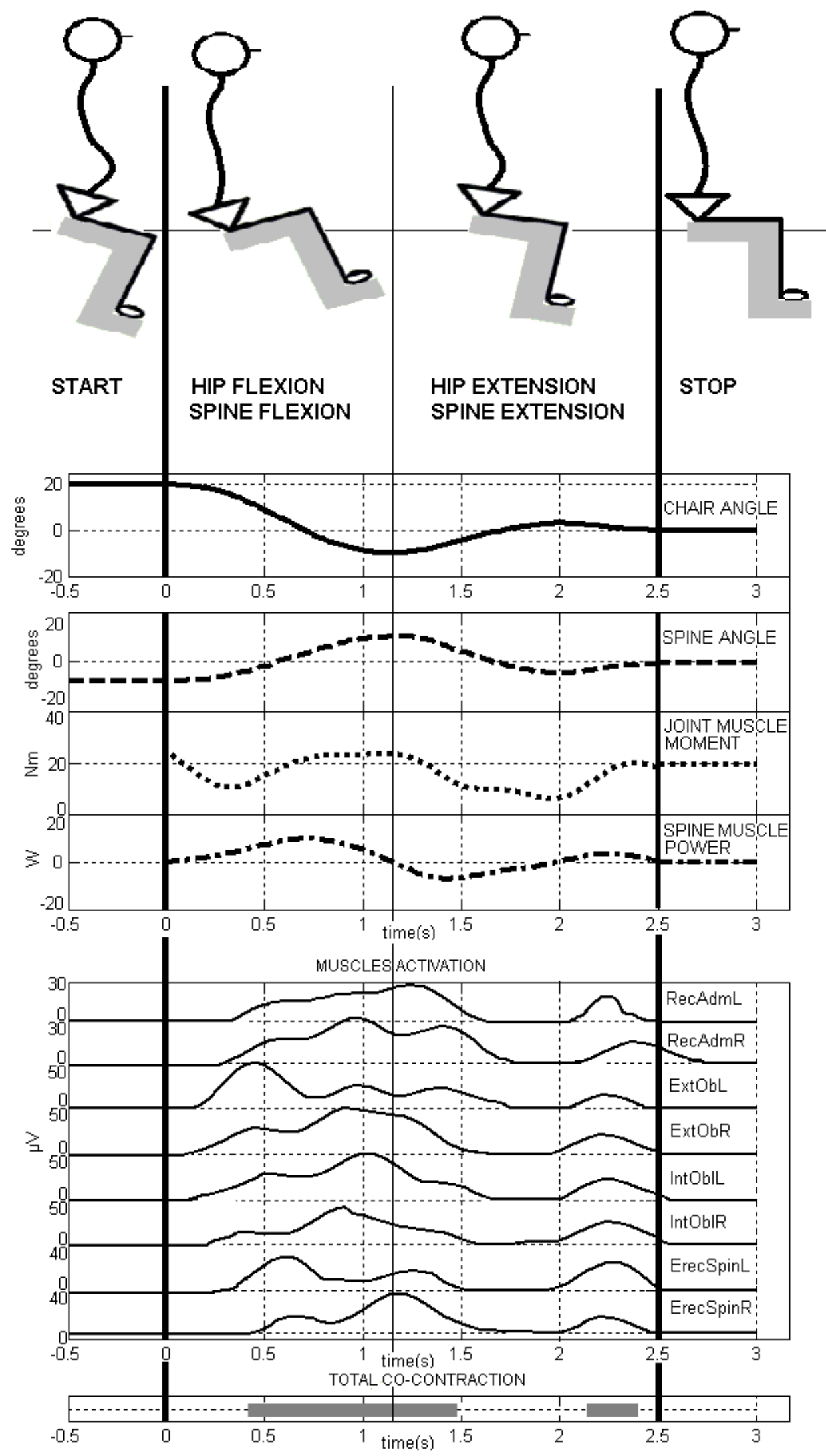

Figure 3: Motion of the lumbar spine and EMG activity during the different phases of the balancing task for one LBP subject. The top graph shows the angular displacement of the swinging chair during the experiment, starting from $20^{\circ}$ and stopping at $0^{\circ}$. Angular displacement, joint moment, muscle power pattern of the lumbar spine are shown. 


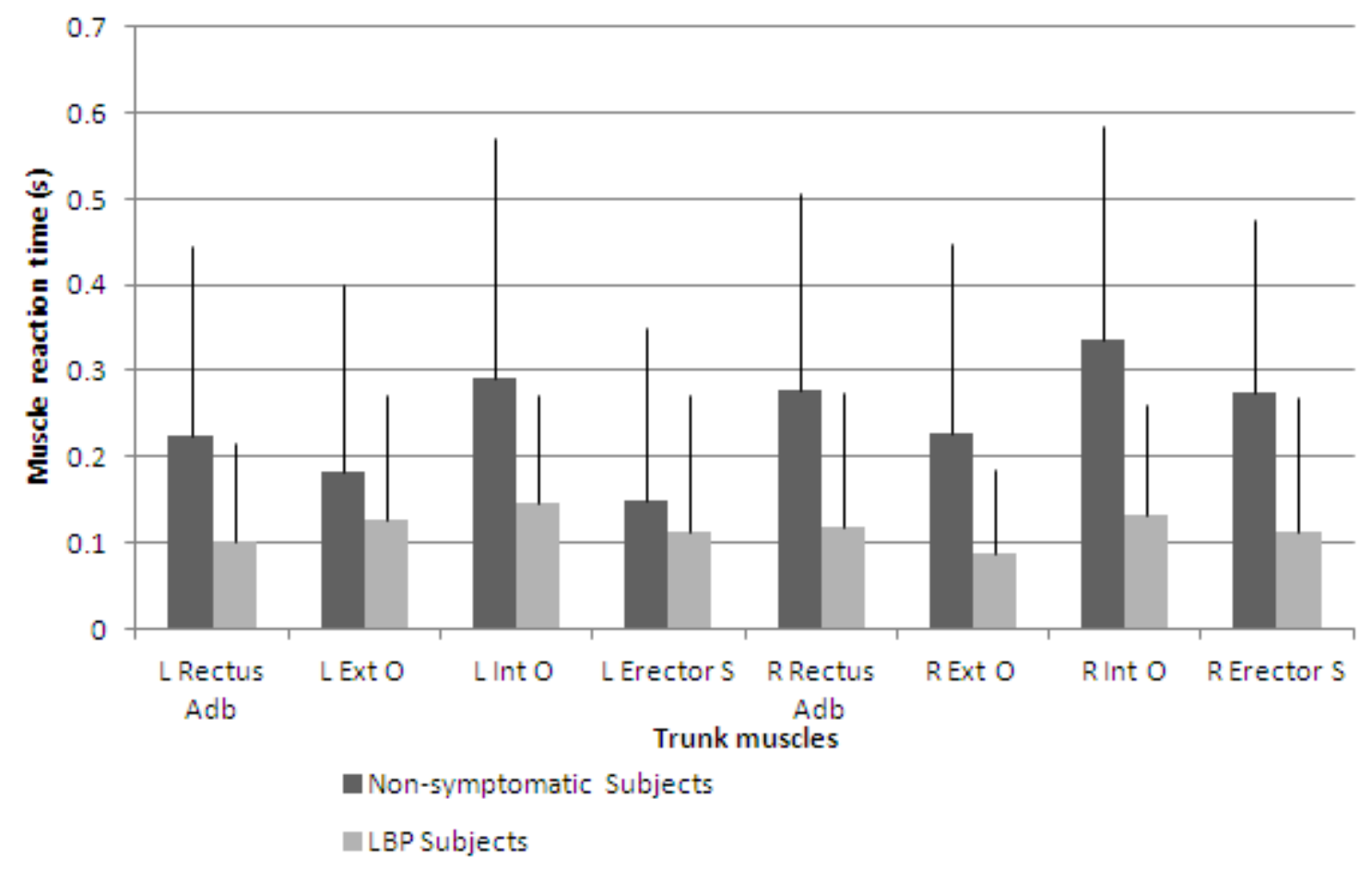

Figure 4: Mean and standard deviation (SD) of the reaction time of trunk muscles during unstable sitting. The error bars represents \pm 1 SD of the measurements of the group.

Significant differences were present between the two groups (p. <0.05). ( $\mathrm{L}=\mathrm{left}, \mathrm{R}=\mathrm{right}$, Rectus $\mathrm{Abd}=$ Rectus Abdominus, Ext $\mathrm{O}=$ External Oblique, Int $0=$ Internal Oblique, Erector $\mathrm{S}=$ Erector Spinae).

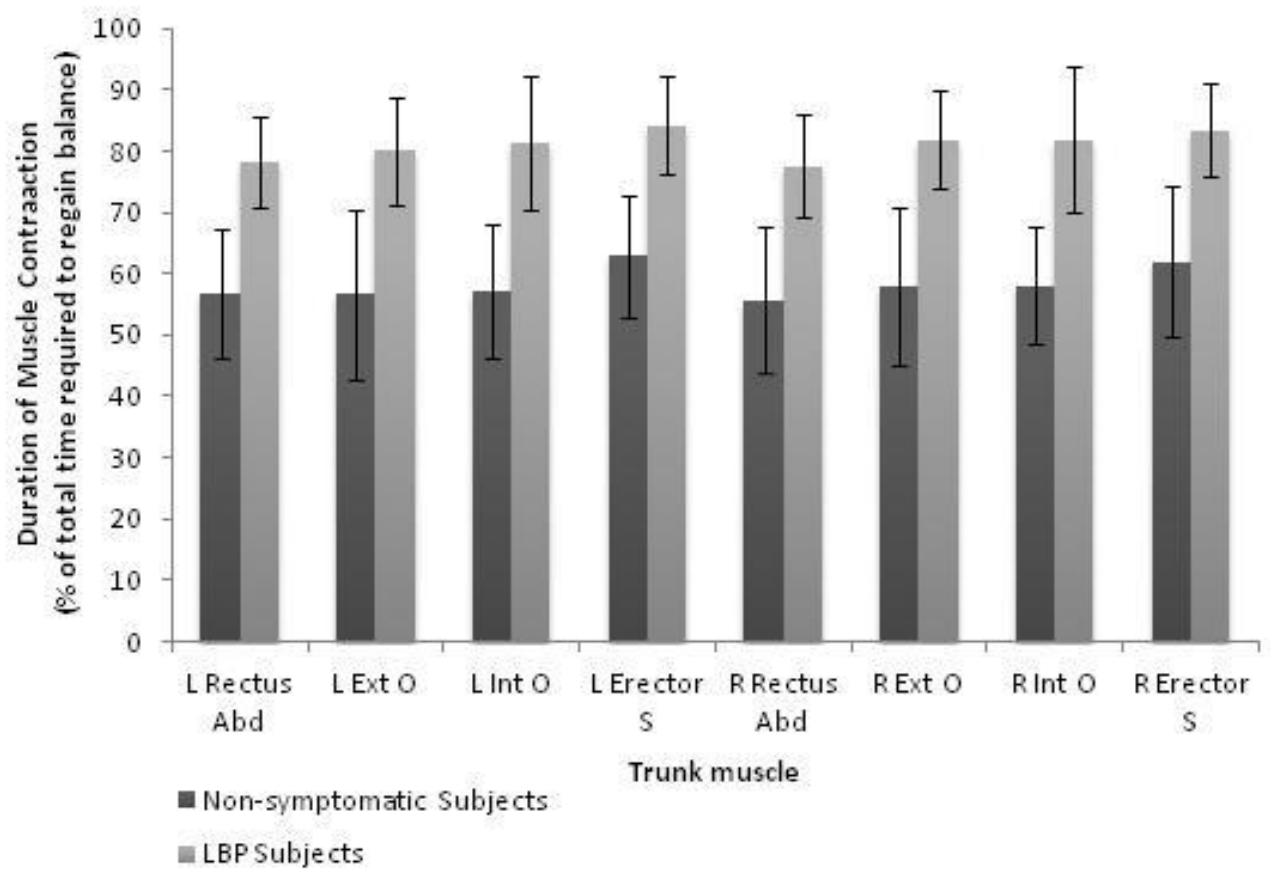

Figure 5: Mean and standard deviation (SD) of duration of muscle contraction as percentage of total time required to regain balance. The error bar represents $\pm 1 \mathrm{SD}$ of the measurements of the group. Significant differences were present between the LBP and healthy subjects (p. $<0.05)$. 


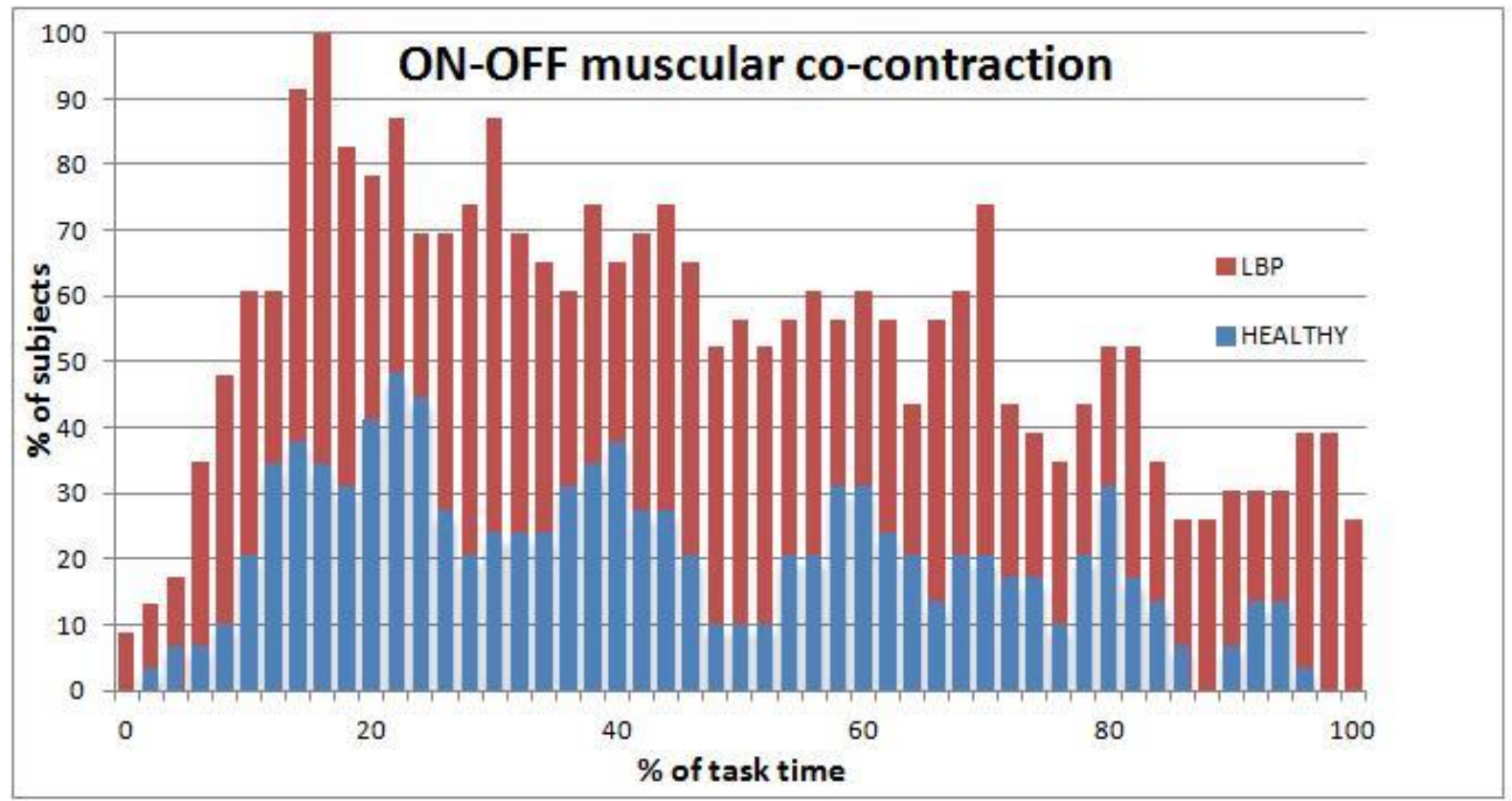

Figure 6: On-off total muscular co-contraction as percentage of number of LBP and healthy subjects.

Table 1 Subjects characteristics

\begin{tabular}{|c|c|c|}
\hline & $\begin{array}{l}\text { Healthy subjects } \\
\qquad(\mathrm{n}=30) \\
\text { mean } \pm \mathrm{SD} \\
\end{array}$ & $\begin{array}{l}\text { LBP subjects } \\
\quad(n=24) \\
\text { mean } \pm \text { SD }\end{array}$ \\
\hline Age (yr) & $31.73 \pm 8.10$ & $36.83 \pm 11.56$ \\
\hline Body Height (m) & $1.676 \pm 0.980$ & $1.689 \pm 0.840$ \\
\hline Body Mass (kg) & $63.89 \pm 13.33$ & $68.96 \pm 11.64$ \\
\hline $\operatorname{BMI}\left(\mathrm{kg} / \mathrm{m}^{2}\right)$ & $22.53 \pm 2.67$ & $24.09 \pm 3.09$ \\
\hline $\begin{array}{l}\text { Oswestry score (scale 0- } \\
100 \text { ) }\end{array}$ & N/A & $19.83 \pm 8.94$ \\
\hline VAS score (scale 0-10) & N/A & $3.80 \pm 1.02$ \\
\hline
\end{tabular}

$\mathrm{N} / \mathrm{A}=$ not applicable 
Table 2 Mean and standard deviation (SD) of velocity, moment and power data for hip and lumbar spine joints

\begin{tabular}{|c|c|c|c|c|}
\hline & \multicolumn{2}{|c|}{ Hip joint } & \multicolumn{2}{|c|}{ Lumbar spine joint } \\
\hline & $\begin{array}{c}\text { Healthy } \\
\text { mean } \pm \\
\text { SD }\end{array}$ & $\begin{array}{c}\mathrm{LBP} \\
\text { mean } \pm \\
\mathrm{SD}\end{array}$ & $\begin{array}{c}\text { Healthy } \\
\text { mean } \pm \\
\text { SD }\end{array}$ & $\begin{array}{c}\mathrm{LBP} \\
\text { mean } \pm \\
\mathrm{SD}\end{array}$ \\
\hline $\begin{array}{l}\text { Velocity } \\
\text { RMS } \\
(\mathrm{rad} / \mathrm{s})\end{array}$ & $\begin{array}{c}0.35 * \pm \\
0.11\end{array}$ & $\begin{array}{c}0.44 * \pm \\
0.11\end{array}$ & $\begin{array}{c}0.16 \pm \\
0.09\end{array}$ & $\begin{array}{c}0.13 \pm \\
0.07\end{array}$ \\
\hline $\begin{array}{c}\text { Velocity } \\
\text { peak-to- } \\
\text { peak (rad/s) }\end{array}$ & $\begin{array}{c}1.50 * \pm \\
0.53\end{array}$ & $\begin{array}{c}1.91 * \pm \\
0.56\end{array}$ & $\begin{array}{c}0.71 \pm \\
0.36\end{array}$ & $\begin{array}{c}0.58 \pm \\
0.34\end{array}$ \\
\hline $\begin{array}{c}\text { Normalized } \\
\text { Moment }\end{array}$ & $\begin{array}{c}0.083 \pm \\
0.04\end{array}$ & $\begin{array}{c}0.081 \pm \\
0.03\end{array}$ & $\begin{array}{c}0.084 \pm \\
0.05\end{array}$ & $\begin{array}{c}0.089 \pm \\
0.03\end{array}$ \\
\hline $\begin{array}{l}\text { Normalized } \\
\text { Maximum } \\
\text { Moment }\end{array}$ & $\begin{array}{c}0.087 \pm \\
0.03\end{array}$ & $\begin{array}{c}0.078 \pm \\
0.02\end{array}$ & $\begin{array}{c}0.072 \pm \\
0.03\end{array}$ & $\begin{array}{c}0.067 \pm \\
0.02\end{array}$ \\
\hline $\begin{array}{c}\text { Normalized } \\
\text { RMS } \\
\text { Power }\end{array}$ & $\begin{array}{c}0.06 \pm \\
0.04\end{array}$ & $\begin{array}{c}0.06 \pm \\
0.03\end{array}$ & $\begin{array}{c}0.013 \pm \\
0.01\end{array}$ & $\begin{array}{c}0.010 \pm \\
0.01\end{array}$ \\
\hline $\begin{array}{l}\text { Normalized } \\
\text { peak-to- } \\
\text { peak Power }\end{array}$ & $\begin{array}{c}0.20 \pm \\
0.14\end{array}$ & $\begin{array}{c}0.19 \pm \\
0.11\end{array}$ & $\begin{array}{c}0.06 \pm \\
0.05\end{array}$ & $\begin{array}{c}0.04 \pm \\
0.04\end{array}$ \\
\hline
\end{tabular}

*indicates significant differences $(\mathrm{p}$-value $<0.005)$

Table 3 Mean and standard deviation (SD) of cross-correlation of the trunk muscle EMG signals of the left and right sides.

\begin{tabular}{|c|c|c|c|c|}
\hline & $\begin{array}{c}\text { Rectus } \\
\text { Abdominis } \\
\text { mean } \pm \\
\text { SD }\end{array}$ & $\begin{array}{c}\text { External } \\
\text { Obliques } \\
\text { mean } \pm \\
\text { SD }\end{array}$ & $\begin{array}{c}\text { Internal } \\
\text { Obliques } \\
\text { mean } \pm \\
\text { SD }\end{array}$ & $\begin{array}{c}\text { Erector } \\
\text { Spinae } \\
\text { mean } \pm \\
\text { SD }\end{array}$ \\
\hline Healthy & $0.70 \pm$ & $0.75 \pm$ & $0.62 \pm$ & $0.67 \pm$ \\
Subjects & 0.11 & 0.21 & 0.15 & $0.09^{*}$ \\
\hline LBP & $0.61 \pm$ & $0.74 \pm$ & $0.69 \pm$ & $0.56 \pm$ \\
Subjects & 0.13 & 0.18 & 0.24 & $0.15^{*}$ \\
\hline
\end{tabular}

*indicates significant differences between healthy subject and LBP groups ( $\mathrm{p}<0.005$ ) 